\title{
A polis acadêmica: do algoritmo e do sentido no trabalho científico
}

\author{
The academic polis: algorithm and meaning in scientific work \\ Maurício Beck ${ }^{1}$ \\ Universidade Estadual de Santa Cruz
}

\begin{abstract}
- RESUMO: neste texto viso discorrer brevemente sobre o funcionamento das redes sociais em aproximação com as redes acadêmicas. Para tanto, trago o conceito de algoritmo a fim de refletir sobre seu funcionamento em relação à avaliação da produção e da circulação de discursos. Abordo o impossível da linguagem matemática para dar conta da inexatidão do sentido e as diferenças entre a doxa e o trabalho científico em termos de argumentação nas redes. Por fim, questiono o lugar da Análise de Discurso Materialista, seja na cidadela acadêmica, seja nas redes digitais e a divisão do trabalho de interpretação em jogo nesses espaços.
\end{abstract}

- PALAVRAS-CHAVE: Redes sociais. Academia. Algoritmo. Sentido; Ilusão/alusão.

- ABSTRACT: in this paper I intend to briefly discourse about the operation of social networks in approach with academic networks. To this end, I bring the concept of algorithm in order to reflect on its operation in relation to the evaluation of the production and circulation of discourses. I address the impossibility of mathematical language to account of the inaccuracy of meaning and the differences between doxa and scientific work in terms of argumentation in the networks. Finally, I examine the place of Materialist Discourse Analysis, either in the academic citadel or in digital networks and the division of interpretation work at stake in these spaces .

- KEYWORDS: Social Networks. Academy. Algorithm. Meaning. Illusion/allusion.

O sistema de trocas comerciais acabou por governar as relações cotidianas do homem com ele mesmo e com seus semelhantes. Todos os aspectos da vida pública e privada são dominados pelo quantitativo. Raoul Vaneigem (2002, [1967])

Eminentes senhores da Academia $^{2}$ : conferem-me a honra de me convidar a oferecer à Academia um relatório sobre a minha pregressa vida antes do Lattes. Não posso infelizmente corresponder ao convite nesse sentido. Quinze anos me separam da condição de sem currículo no sistema; espaço de tempo que medido pelo calendário talvez seja breve, mas que é

\footnotetext{
1 Doutor em Letras. Professor visitante pelo PPGLLR-UESC. E-mail: pardalbeck@gmail.com

2Neste texto tomo a liberdade de - além de citar, parafrasear e comentar formulações e conceitos de autores acadêmicos e não acadêmicos - parodiar pequenos trechos de textos reconhecidos no campo das ciências humanas e da literatura. O jogo de paráfrase e de paródia foi o modo que encontrei de questionar na forma o que problematizo no conteúdo. Trata-se de provocar certa dialética e, assim, visar a forma material em foco.
} 
infindavelmente longo para atravessar a galope como eu o fiz, acompanhado em alguns trechos por pessoas excelentes, conselhos, aplauso e música rock, mas no fundo sozinho, pois, para insistir na imagem, todo acompanhamento se mantinha bem recuado diante da barreira.

De um lado os integrados, de outro os apocalípticos. Se os integrados raramente teorizam, já o apocalipse é uma obsessão dos dissidentes. A integração é a realidade concreta dos que não dissentem. As imagens do Apocalipse são decalcadas do discurso sobre as redes sociais; a imagem da integração emerge da leitura do discurso das redes sociais. Mas até que ponto não nos encontramos ante duas faces de um mesmo problema, e não representarão esses discursos apocalípticos o mais sofisticado produto oferecido ao meio acadêmico? Então a fórmula "apocalípticos e integrados" não sugeriria a oposição entre duas posições-sujeito (e os dois termos não teriam valor de substantivo), mas a predicação de adjetivas complementares, adaptáveis a esses mesmos produtores de uma "crítica em rede das redes sociais".

Com essa aproximação entre os meios acadêmicos e as atuais redes sociais, disseminadas pela internet, quero lembrar que as ditas redes sociais surgiram no seio do meio universitário. Não por acaso, seu funcionamento automatiza muito dos ritos de circulação acadêmicos: o botão virtual de compartilhar, uma forma de citação direta, em alguns casos, com as devidas referências à fonte (pode-se optar fazer menção ao apud ${ }^{3}$ ); o botão de curtir parodia a avaliação dos pares por meio de um clique e assegura o mais importante: a mensuração do fator de impacto na comunidade de uma dada postagem. (Um artigo nunca citado seria um artigo que flopou).

A mensuração do fator de impacto nas redes, aliás, independentemente se falamos de meios acadêmicos ou de redes sociais, funciona de modo cada vez mais automatizada, por meio de algoritmos informatizados. Mas o que é um algoritmo? Segundo Pedro Domingos:

Um algoritmo é uma sequência de instruções que informa ao computador o que ele deve fazer. Os computadores são compostos por bilhões de minúsculas chaves chamadas transistores, e os algoritmos ligam e desligam essas chaves bilhões de vezes por segundo. [...] todos os algoritmos não importando sua complexidade, podem ser reduzidos a apenas três operações: E, OU e NÃO. [...] Frequentemente as pessoas acham que os computadores só lidam com números, mas não é isso que ocorre. Os computadores são pura lógica. Os números e a aritmética são feitos de lógica, assim como tudo mais que existe em um computador. (DOMINGOS, 2015, p. 2-4)

Se acreditarmos em Harari (2016, p. 91), o algoritmo é o conceito singular mais importante deste século. "Um algoritmo é um conjunto metódico de passos que pode ser usado na realização de cálculos, na resolução de problemas e na tomada de decisões." Tais algoritmos eletrônicos "não conscientes mas altamente inteligentes" estariam empenhados em "nos conhecerem melhor que nós nos conhecemos" (p. 399), pela via do monitoramento e do processamento das operações e de todas interlocuções que realizamos cotidianamente nas redes digitais.

\footnotetext{
3 Outro aspecto que anima o cotidiano das redes (ou potencializa um fluxo crescente de dados, diriam os dataístas) é o princípio do comentário, para não esquecermos Foucault: "A repetição indefinida dos comentários é trabalhada do interior pelo sonho de uma repetição disfarçada: em seu horizonte não há talvez nada além daquilo que já havia em seu ponto de partida, a simples recitação.[...] o novo não está no que é dito, mas no acontecimento de sua volta.” (1996, [1970], p.25-26).
} 
Talvez se possa afirmar que o registro e o processamento automático de nossos gestos operacionais, em termos hegelianos, visaria realizar a ideia da atividade alienada traduzida em pura linguagem lógico-matemática, como um poder separado dos indivíduos. Entretanto, o processo de transformar qualidade em quantidade na mensuração dos fatores de impacto joga com um impossível que concerne à especialidade da Análise de Discurso: o do sentido, pois osentido é da ordem do inexato, segundo Orlandi (2017, p. 206):

A distinção, a exatidão, o segmentável, fazem parte de uma reflexão que deixa de lado a discursividade, a relação não unívoca. Nós trabalhamos com o que se mistura, o que se presta a equívoco, o que nem sempre se pode separar em unidades distintas, tudo junto e misturado.

Em contraste, o projeto, embalado pela ideia de que "não há nada que fuja aos números", no dizer de Leibniz, tem suas bases epistemológicas em concepções matemáticas que remontam ao platonismo ${ }^{4}$. Mas ganha um novo fôlego com o discurso do método científico moderno em Galileu e Kepler. Trata-se desde então de medir o que era antes imensurável e representar o que ainda não foi. A matemática, suposta como a língua da ciência, produziria o livro da natureza escrito em linguagem numérica. Uma utopia ou distopia da matematização? Eis algo paradoxal: uma vez que a finalidade do aspecto matemático da linguagem segundo Zerzan (2016, [2009]), é o isolamento mais completo entre o conceito e o sentido. "O número é uma nomeação empobrecida", ainda segundo Zerzan (2016, [2009] p.10), "no distanciamento e na separação reside o cerne da matemática: a redução discursiva de padrões, estados e relações que nós inicialmente percebíamos como totalidade." (2016, [2009] p.10).

Se o projeto de mensuração flerta com um impossível, por outro lado, o compartilhar/partilhar sentidos estão ligados ao efeito-rumor nos meios digitais lança, para Adorno e Silveira (2017, p. 6) à seguinte questão: "Qual o lugar dos algoritmos (ou processos de normatização digital?) nessa conjuntura de "pós-verdade" - os algoritmos desempenham outro tipo de regulação dos discursos?" Pós-verdade, fakenews são temas e problemas correntes neste começo de século XXI. Diante disso, cabe uma indagação: estamos testemunhando a volta à cena do discurso (via escritoralidade ${ }^{5}$ ) dos antigos sofistas, após milênios de exclusão socrático-platônica? A força da doxa dos terraplanistas contra a episteme copernicana? Ou, avançando em questões mais profícuas: como se dá a constituição, a formulação e a circulação da doxa em tempos de redes sociais? O que diferencia a doxa da episteme contemporaneamente? Como ensaio de uma resposta começo abordando o funcionamento da episteme. Talvez um aspecto universal em termos de prática científica, a

4 Não por acaso, a noção de materialidade específica em Althusser (2008, [1995]), herdada pela Análise de Discurso, remete a Aristóteles, que tomou certo distanciamento crítico com relação ao vetor matemático platônico. A materialidade de uma palavra, ou de uma piscadela ou de um discurso interno não é a a mesma da de um meme, ou de um sinal de arma com a mão. 5 Por que escritoralidade? Porque o sentido é fechado, mas ao mesmo tempo é provisório; ele é publicado, mas ao mesmo tempo ele desaparece, de um momento para o outro; é legítimo, mas não é legítimo para todos, mas para um certo leitor (quem aqui não publica suas coisas no facebook, e não tem um leitor?). Textos que podem ser acessados no mundo inteiro, embora o mundo não esteja interessado nessas publicações, mas tem um pequeno número de leitores que está. [...] Nós temos aí um discurso de escrita, ao mesmo tempo com as características da oralidade, sem as exigências do discurso de escrita, mas ao mesmo tempo com os benefícios do discurso de escrita. (GALLO, 2012, p. 60) 
despeito das metodologias específicas a cada ciência, é a necessidade de exposição e argumentação entre pares.

Em uma perspectiva discursiva, a prática de argumentação enquanto confronto entre discursos em dadas condições de produção não se reduz a um epifenômeno sem eficácia. A prática da argumentação, não como elocução intencional, mas enquanto parte de uma ritualística (procedimentos científicos, entre estes, a submissão de dados resultados ou conclusões de análises à crítica dos pares) em que discursos entram em relação, em cooperação, em confronto pode/deve acarretar transformações de sentido.

Os encontros científicos vivem cheios de disputas. Há colóquios universitários em que o conferencista mal discursou trinta segundos e já se ouvem perguntas e comentários devastadores da plateia. É instrutivo examinar os procedimentos aos quais um relatório escrito é submetido para possível publicação numa revista científica, sendo depois enviado pelo editor a juízes anônimos que têm como tarefa fazer as seguintes perguntas: $\mathrm{O}$ autor fez alguma besteira? Existe alguma coisa nesse trabalho que seja suficientemente interessante para ser publicada? Os resultados mais importantes foram descobertos por outra pessoa? A argumentação é adequada, ou o artigo deveria ser reavaliado depois que o autor realmente demonstrar aquilo que nesse trabalho, por ora, é ainda apenas especulação? (SAGAN, 2006, [1995], p. 51)

O valor da crítica, em seu potencial transformador (da matéria-prima ideológica em conhecimento em termo althusserianos), é uma hipótese teórica a ser verificada em trabalhos de análise posteriores. De todo modo, nessa ótica, é a exterioridade, a das práticas rituais de dadas instâncias da comunidade científica, que seria determinante no funcionamento da argumentação em ciência e não uma suposta interioridade autossuficiente do argumentador.

Ademais, se poderia mostrar que há diferenças nos modos como os discursos são postos em contato ou confronto, afetando seu funcionamento com relação aos processos parafrásticos e polissêmicos $\mathrm{O}$ funcionamento da argumentação, enquanto antifonia, talvez possa ser melhor entendido em cotejo com a distinção entre o lúdico, o polêmico e o autoritário. Conforme Orlandi:

em relação à tensão entre os dois grandes processos - a paráfrase (o mesmo) e a polissemia (o diferente) - que consideramos ser o fundamento da linguagem, diríamos que o discurso lúdico é o polo da polissemia (a multiplicidade de sentidos), o autoritário é o da paráfrase (a permanência do sentido único, ainda que nas diferentes formas) e o polêmico é aquele em que melhor se observa o jogo entre o mesmo e o diferente, entre um e outro sentido, entre paráfrase e polissemia (ORLANDI, 2011, [1983] p.155)

Em minha leitura, a argumentação em ciência estaria para o discurso polêmico, discurso no qual há uma polissemia controlada, certo equilíbrio, ainda que tenso, entre paráfrase e polissemia. $\mathrm{O}$ embate argumentativo se realizaria via jogo verbal em que o litígio 
de explicações/interpretações sobre dado objeto ${ }^{6}$ é regrado pelo rito de procedimentos próprios ao científico. Em outras palavras, tratear-se-ia de uma troca guiada, conforme a formulação de Feyerabend:

alguns ou todos os participantes adotam uma tradição bem específica e aceitam apenas aquelas respostas que correspondem a seus padrões. Se um dos lados ainda não se tornou um participante da tradição escolhida, será atormentado, persuadido, 'educado' até que o faça - então a troca começa. A educação é separada de debates decisivos, ela ocorre em um estágio anterior e garante que os adultos irão se comportar de modo apropriado. Um debate racional é um caso especial de uma troca guiada. (FEYERABEND, 2007, [1975],p. 305-306)

A troca guiada só se realiza, entretanto, via persuasão ou educação prévia dos participantes. E a educação, separada dos debates decisivos, segundo o filósofo, parece funcionar com base no discurso pedagógico autoritário, se remontarmos às análises de Orlandi (2011, [1983]). De outro lado, a troca guiada, para Feyerabend (2007, [1975]), contrasta com a troca aberta, na qual "a tradição adotada pelas partes envolvidas não é especificada no início e desenvolve-se à medida que a troca prossegue. [...] Uma troca aberta não dispõe de um órganon, embora possa inventar um, não há lógica, embora novas formas lógicas possam surgir em seu curso". (idem, p.306, grifo nosso). Em suma, a troca aberta estaria para o discurso lúdico, assim como a troca guiada estaria para o discurso polêmico. A referência e o cotejo com essas com noções de Feyerabend se fazem pertinentes tendo em conta que este filósofo questionou a universalidade de um suposto método científico e defendeu a historicidade da racionalidade científica, uma tradição particular entre outras, com seuórganon particular.

Com o contraste entre as noções de a troca guiada e de troca aberta, proposta por Feyerabend (2007, [1975]), em cotejo com o funcionamento do discurso lúdico e o discurso polêmico, na leitura de Orlandi, podemos pensar a especificidade da argumentação (enquanto antifonia) em ciências. E, assim, mostrar que, conforme as regras de procedimento da agonística verbal se alteram, as condições de reprodução/transformação em termos de sentido e, mais especificamente, em termos de produção de conhecimento também se veem alteradas. De modo que a prática da argumentação em ciência teria sua especificidade definida pelo conjunto de procedimentos que dão as condições de possibilidade da agonística ou da polêmica com relação a dado objeto de conhecimento. Ora, é bom lembrar que em termos bachelardianos, as verdades só adquirem sentido ao fim de uma polêmica, com a retificação dos erros. Com a ressalva que, segundo Bachelard (1977, [1949]), os erros têm uma função positiva na produção de conhecimento. Os erros constituem um magma desorganizado, já as verdades se organizariam em um sistema racional.

Tratei de algumas características do discurso acadêmico. Resta perguntar: em contraste, como funciona a formulação e a circulação do discurso nas redes sociais? Em

6 Talvez o litígio em ciência funcione como um dos modos de trabalhar (transformar) a(s) imagens(s) que os argumentadores fazem do referente (objeto científico). 
primeiro lugar, não parece haver um funcionamento homogêneo. Cada ambiência, com seus respectivos algoritmos eletrônicos em atividade, parecer ter suas especificidades. Contudo, os algoritmos em questão são inacessíveis e opacos aos sujeitos usuários destas redes. Este é um importante diferencial entre tais redes e as comunidades científicas. Os procedimentos, ritos e algoritmos de avaliação e circulação que normatizam o discurso acadêmico não são a priori opacos aos pesquisadores. Por essa mesma razão, há ainda possibilidade de autocrítica ao discurso e ritos racionalistas da academia, (como fizeram Feyerabend (2007, [1975]) ou Tragtenberg (2002, [1979]).A doxa das redes sociais, por outro lado, muitas vezes, não parece funcionar como um discurso lúdico (na acepção de Orlandi (2011, [1983])) ou como troca aberta (na acepção de Feyerabend (2007, [1975]), mas antes como um potente disseminador do discurso da injuria ${ }^{7}$ conforme a atual proliferação de expressões de ódio no ciberespaço. As razões dessa proliferação podem ter a ver com distância física entre os usuários, encorajando pulsões inibidas em outras circunstâncias, mas também são indícios do funcionamento dos algoritmos que regulam os fluxos de dados em determinadas redes sociais. Enfim, não me estenderei mais em reflexões, talvez precipitadas, sobre um fenômeno discursivo ainda em expansão. Investigações sobre os efeitos dos algoritmos já estão sendo realizados no campo discursivo, enfrentando o obstáculo de os próprios algoritmos permanecerem em uma caixapreta - tanto às massas de usuários quanto aos pesquisadores.

\section{Desvelamento de opacidades}

A crítica à ideologia é feita nos chamados cursos críticos, que desempenham a função de tranquilizante no meio universitário.

(TRAGTENBERG, $2002,[1979])$.

Após algumas reflexões sobre os modos de funcionamento do discurso em redesdigitais ou acadêmicas - gostaria de tecer breves considerações sobre o papel da práxis do analista de discurso nestas redes, sobretudo na cidadela acadêmica, onde esse metier tem se realizado com maior intensidade no Brasil há algumas décadas. A questão é a seguinte: existe uma tendência que poderíamos chamar, um tanto ironicamente, de marxismo acadêmico, que consiste em procurar de que maneira as condições materiais de existência podem encontrar nos sentidos do discurso a sua alusão via ilusão. Remontemo-nos ao freudismo, base para Althusser alavancar sua teorização do funcionamento da ideologia pelo um prisma da interpretação onírica. Eis o que nos diz Rouanet:

[...] no plano social, filogenético como ele [Freud] diria, existe a utopia de uma sociedade totalmente transparente para si mesma. É utópico porque nunca a sociedade será totalmente transparente para si mesma, e, no entanto, a psicanálise, no plano coletivo, no plano social, não pode deixar de se colocar esse ideal. Ele também disse isso no Mal-Estar na Civilização, que um dia será possível ao homem renunciar aos mecanismos de defesa, como o recalque, por exemplo (um mecanismo infantil de fuga), e a sociedade passe

\footnotetext{
7 Para a psicanálise, a injúria estaria na base de nosso laço social. Freud (1991, [1893]) cita a observação espirituosa de Hughlings Jackson sobre o fundador da civilização: teria sido o primeiro indivíduo que, ao invés de flechar seu inimigo, lançou um insulto contra ele.
} 
a ser regida por Logos! Quando a razão assumir o comando, o controle social e a regulamentação pulsional se farão através da organização racional da sociedade. Isso é realizável? Obviamente que não. Então temos duas utopias: no plano individual, a utopia de um psiquismo transparente para si mesmo, e, no plano social, a utopia de uma sociedade regida pela razão. Duas coisas inatingíveis e irrenunciáveis. (ROUANET, 2004)

Utopia da transparência do sócio-histórico casada com a utopia da transparência do sujeito. Inatingíveis e irrenunciáveis. Sua renuncia redundaria ou na perpetuação de uma razão cativa (ROUANET, 1985) ou na disseminação de uma razão cínica (SLOTERDIJK, 2012, [1983]). Uma teoria da opacidade do sujeito e da história, como a de Althusser ou a de Pêcheux, não escapa ao impasse do intangível irrenunciável. Ela o deflagra em confronto como um mal-estar teórico: se a função da teoria é jogar luz na opacidade que ela mesma postula, esse desvelamento é o irrenunciável conhecimento da opacidade (objetivante ou aproximativa porque visa ser fiel ao funcionamento do objeto seja ele discurso, ideologia ou inconsciente). Althusser (2008, [1995]), com mote na interpretação freudiana dos sonhos, visou produzir conhecimento teórico do ideológico pela via da alusão que a ilusão (da representação imaginária entre os sujeitos) conteria. A plena transparência do laço social é o inatingível irrenunciável de um projeto teórico-crítico da ideologia e do discurso.

Contudo, se não atingimos a plena transparência da instância ideológica, algum efeito a prática analítica provocaria. Qual seria este, para além do conhecimento teórico? A terceira modalidade discursiva de funcionamento subjetivo, o sujeito da desidentificação não seria o efeito esperado, por Pêcheux,(1997, [1975]) da prática teórica (em fusão com o movimento revolucionário)? Contemporaneamente, algumas militâncias em redes sociais também projetam, como resultado de suas práticas desconstrutivas, um efeito sujeito desconstruído ("o desconstruídão").

Tanto o teórico sujeito desidentificado quanto o imaginário sujeito descontruído incorreram, todavia, em contradições incontornáveis. Outro sujeito, no entanto, parece fazer laço social e constituir um discurso que, se não supera as contradições, as contorna. Este efeito-sujeito cínico (estudado por Sloterdijk (2012, [1983]), Žižek (1996), Baldini e Di Nizo (2015)) parece funcionar no avesso da proposta althusseriana: reproduz um desconhecimento do ideológico via alusão (antecipação da crítica). Uma ilusão via alusão ("Eu sei muito bem o que estou fazendo, mas mesmo assim eu o faço"). Eis um efeito-sujeito que resultaria da prática da análise ideológica e discursiva. De minha parte, suspeito que talvez o problema não esteja neste efeito inesperado em si, mas na interlocução, no laço social que lhe dá um lugar. Quem é o interlocutor da piscadela cínica? Como ele a replica? Com um menear a cabeça? Com um cruzar de braços? Importante lembrar que Sloterdjik (2012, [1983]) em sua crítica da falsa consciência cínica (outra versão da contraditória figura do Barão de Munchhausen?) toma como momento histórico impar na disseminação em massa do discurso cínico a República de Weimar do entre guerras, não por acaso, a época imediatamente anterior à ascensão do fascismo de massa.

Por falar em massas, parece pertinente nos perguntarmos não só pela constituição, mas também pela circulação de dados discursos em tempos de interlocução em redes. Essa perspectiva, entretanto, não estava ausente em Marx desde os tempos da Crítica da Filosofia do Direito de Hegel. Quando e como a teoria ganha as massas? Ora, "É certo que a arma da 
crítica não pode substituir a crítica das armas, que o poder material tem que ser derrocado pelo poder material, mas também a teoria transforma-se em poder material logo que se apodera das massas" (MARX, 1977, [1844], p. 8). Ainda que com formação acadêmica, Marx escrevia para não-acadêmicos. Tratava-se de romper a divisão social entre trabalho intelectual e trabalho braçal.

Em A Ideologia Alemã, Marx e Engels (2007, [1845-1846]) correlacionavam a divisão entre trabalho material e trabalho intelectual com a separação entre cidade e campo. Desde então essa divisão não cessou de se transformar sem, contudo, deixar de persistir. Os supostos privilégios do dito trabalho intelectual de outrora foram corroídos em concomitância com o declínio da necessidade da força física no modo de produção capitalista contemporâneo. $\mathrm{O}$ corpo do trabalhador confinado de hoje diverge do corpo do trabalhador braçal de ontem. E as formas de sofrimento mudaram nesse sentido. Dito isso, creio, ainda assim, que a divisão social do trabalho de interpretação (PÊCHEUX, 1994, [1982]) reproduz aquela divisão enunciada por Marx, no século XIX em outros patamares. E o lugar da produção acadêmica, do trabalho confinando e sedentário do produtor de conhecimento é constitutiva do processo de divisão desigual em questão.

Antes de finalizar, resta ainda uma última questão imperdoável: qual seria o papel dos analistas de discurso nas redes sociais, ou na circulação de sentidos entre as massas? Podemos e devemos permanecer retraídos no claustro da cidadela universitária? Insistiremos no confinamento para realizarmos análises somente para analistas lerem? Encaminho uma possível resposta, colega: remontemo-nos à conhecida Tese 11 sobre Feuerbach de Marx e Engels (2007, [1845], p. 539): “os filósofos apenas interpretaram o mundo de diferentes maneiras; porém, o que importa é transformá-lo.' Heidegger (2011, [1969]) retrucou esta tese provocativamente: uma mudança de mundo pressupõe uma mudança no conceito de mundo. Essa mudança de concepção só pode se realizar por meio de uma interpretação. De fato, mas essa proposta já estava contida na tese marxiana. Interpretar para transformar, em termos discursivos: questionar o óbvio do sentido e a saturação do ideológico. No entanto, tal transformação implica, em superar a cisão entre prática e teoria, divisão social do trabalho, via práxis (ou entre a prática teórica e outras práticas, segundo os termos althusserianos). Trata-se então, para não recairmos em uma delinquência acadêmica (Tragtenberg, 2002, [1979]), de superarmos o confinamento do âmbito universitário para fazer circular nossas interpretações.

No entanto, é preciso não esquecer que já não compreendemos ideologia enquanto falsa consciência, ou ocultação da verdade. Em Análise de Discurso, conceituamos ideologia como um mecanismo de produção de evidências por efeito de saturação de um sentido, tido como $o$ sentido. Nosso metier concentra-se em desvelar a dimensão polissêmica da linguagem humana em imbricação com sua exterioridade. Visamos lançar uma questão bem imbecil: por que esses sentidos e não outros? Efeito de polissemia e de transvaloração de todos os valores? Será que me excedo, colega da academia? Com base em Sousa (2007),talvez eu possa contraargumentar que nosso ceticismo político atual é sintoma de nossa maior inibição:a da incapacidade subjetiva para imaginar um futuro outro. Nosso imaginário de futuro anda saturado de $u m$ sentido, aquele de nosso presente perpetuado.

Com efeito, Žižek (2005) pensa a utopia não como uma projeção de um mundo perfeito, totalmente ordenado no estilo da ficção de Thomas Morus, mas como a completa ausência de coordenadas sociais de cooperação. O dia em que teremos de inventar novas coordenadas porque as velhas já não funcionarão mais. "É somente quando entramos em desespero e não sabemos mais o que fazer que mudanças podem ser implementadas - nós 
temos de passar por este ponto zero de desesperança." (ŽIŽEK, 2019). É curioso notar estranhas ressonâncias com uma afirmação de Sagan:

O óbvio é às vezes falso; o inesperado é às vezes verdadeiro. [...] A atual cultura global é uma espécie arrogante recém-chegada [...] Nenhuma nação, nenhuma religião, nenhum sistema econômico, nenhum corpo de conhecimento é capaz de saber todas as respostas que concernem a nossa sobrevivência. Deve haver muitos sistemas sociais que funcionariam muito melhor do que qualquer um hoje existente. Segundo nossa tradição científica, nossa tarefa é descobri-los. (SAGAN, 2017, [1980], p.418)

Dei conta de transformar meu mal-estar acadêmico em uma narrativa de sofrimento consistente? Seja como for, no conjunto eu alcanço o que queria alcançar. Não se diga que o esforço não valeu a pena. No mais não quero nenhum julgamento dos colegas, quero apenas difundir meus gestos de leitura; faço tão somente um relatório; também aos senhores, eminentes membros da Academia, só apresentei um relatório.

\section{REFERÊNCIAS}

ADORNO, Guilherme; SILVEIRA, Juliana. Pós-verdade e fake news: equívocos do político na materialidade digital. Anais do VIII SEAD. Disponível em :http://anaisdosead.com.br/8SEAD/SIMPOSIOS/SIMPOSIO\%20V Gadorno\%20e\%20JSilvei ra.pdf. Acesso em 03 janeiro 2019.

ALTHUSSER, Louis. [1995] Sobre a Reprodução. Tradução de Guilherme João de Freitas Teixeira. Introdução de Jacques Bidet. 2 ed. Petrópolis: Vozes, 2008.

BACHELARD, Gaston. [1949] O Racionalismo Aplicado.Tradução de Nathanael C. Caixeiro. Rio de Janeiro: Zahar Editores, 1977.

BALDINI, Lauro José Siqueira; DI NIZO, Patrícia Leal. O Cinismo como prática ideológica. Estudos da Linguagem. Vitória da Conquista, v. 13, n. 2 p. 131-158. dez de 2015.

DOMINGOS, Pedro. O Algoritmo Mestre. Como a busca pelo Algoritmo de Machine Learning definitivo recriará nosso mundo. São Paulo: Novatec, 2017.

FEYERABEND, Paul. [1975] Contra o Método. Tradução de Cezar Augusto Mortari. São Paulo: Unesp, 2007.

FOUCAULT, Michel. [1970] A ordem do discurso. Tradução de Laura Fraga de Almeida Sampaio. Edições Loyola, 1996.

FREUD, Sigmund. [1893]. Sobre el mecanismo psíquico de fenómenos histéricos. In: .Obras completas.v. 3. Buenos Aires: Amorrortu, 1991.

GALLO, Solange. Novas Fronteiras para a autoria. Organon, Porto Alegre, n. 53, p. 53-64, julhodezembro, 2012,

HARARI, YuvalNoah. Homo Deus:Uma breve história do amanhã. Tradução de Paulo Geiger. Editora Companhia das Letras, 2016.

HEIDEGGER, Martin. [1969] Heidegger sobre Marx e a mudança de mundo. 2011. (01 min 33s). Disponível em https://www.youtube.com/watch?v=HIXWnhwlrpk Acesso em 17 novembro 2018. 
MARX, Karl; ENGELS, Friedrich. [1845-1846].A Ideologia Alemã. Crítica da novíssima filosofia alemã em seus representantes Feuerbach, B. Bauer e Stirner e do socialismo alemão em seus diferentes profetas. Organização, tradução, prefácio e notas de Marcelo Backes. Rio de Janeiro: Civilização Brasileira, 2007.

MARX, Karl. [1844] Crítica à Filosofia do Direito de Hegel - Introdução.Temas de Ciências Humanas. n. ${ }^{\circ}$ 2. Editorial Grijalbo. 1977.

ORLANDI, Eni Puccinelli. [1983] A linguagem e seu funcionamento: as formas do discurso. 6.ed. Campinas: Pontes Editores, 2011.

.Eu, Tu, Ele: Discurso e real da história. 2. ed. Campinas: Pontes, 2017.

PÊCHEUX, Michel. [1982] Ler o arquivo hoje. Tradução de Maria das Graças L. Morim do Amaral. In: ORLANDI, Eni Puccinelli. Gestos de leitura. Da história no discurso. 3d. Campinas: Unicamp, 1994. p. 49-59.

. [1975] Semântica e Discurso: Uma Crítica à Afirmação do Óbvio. Tradução de

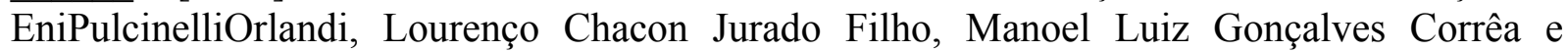
Silvana Mabel Serrani. 3. ed. Campinas. Ed. Unicamp, 1997.

ROUANET, Sérgio Paulo. Dupla Utopia Psicanalítica. Percurso, n. 33. 1 sem. 2004. Disponível em: < http://www2.uol.com.br/percurso/main/pcs33/33Entrev.htm>. Acesso em: 03 dezembro2017.

. A razão cativa. São Paulo: Brasiliense, 1985.

SAGAN, Carl. [1980] Cosmos. Tradução de Paulo Geiger. São Paulo: Companhia das Letras, 2017.

. [1995] O Mundo Assombrado pelo Demônios: A ciência vista como uma vela no escuro. Tradução de RosauraEichemberg. São Paulo: Companhia das Letras, 2006.

SLOTERDIJK, Peter. [1983] Crítica da Razão Cínica. Tradução de Marco Casanova, Paulo Soethe, Pedro Costa Rego, Maurício Mendoça Cardozo e Ricardo Hiendlmayer. São Paulo: Estação Liberdade, 2012.

SOUSA, Edson Luiz André. Uma Invenção da Utopia. São Paulo: Lumme, 2007.

TRAGTENBERG, Maurício. [1979] A Delinquência Acadêmica. Verve. São Paulo, n. 2, p.175-184, 2002. Disponível em:

https://revistas.pucsp.br/index.php/verve/article/download/4618/3208. Acesso em 20 setembro 2018.

VANEIGEM, Raol. [1967] A Arte de Viver para as novas gerações. São Paulo: Conrad, 2002.

ZERZAN, John. [2009] Número: sua origem e evolução. Tradução do Coletivo de Traduçãoe publicações colaborativas do grupo Anarquia Verde. s.l.Contraciv, 2016.

ŽIŽEK, Slavoj. A Coragem da Desesperança:Crônicas de um ano em que agimos perigosamente. Tradução de Renato Aguiar. Rio de Janeiro: Zahar, 2019.

1996.

Um Mapa da Ideologia. Tradução de Vera Ribeiro. Rio de Janeiro: Contraponto,

ŽIŽEK! Direção de Astra Taylor. Produção de Lawrence Konner. 78 min. Color. EUA, Canadá, 2005. 1 DVD.

Textos parodiados:

ALTHUSSER, Louis. [1995] Sobre a Reprodução. Tradução de Guilherme João de Freitas Teixeira. Introdução de Jacques Bidet. 2 ed. Petrópolis: Vozes, 2008. 
ECO, Umberto.[1964] Apocalípticos e integrados. Tradução de Pérola Carvalho. São Paulo: Perspectiva, 1970.

FOUCAULT. Michel. [1974] A Verdade e as Formas Jurídicas. Tradução de Roberto Cabral de Melo Machado e Eduardo Jardim Morais). Rio de janeiro: Nau, 2001.

KAFKA, Franz. [1917] Um relatório para a Academia. In: . Um médico rural. Tradução de Modesto Carone. São Paulo: Companhia das Letras, 1999.

Recebido em: dezembro de 2018. Aprovado em: fevereiro de 2019.

\section{Como citar este trabalho:}

BECK, M. A polis acadêmica: do algoritmo e do sentido no trabalho científico. Traços de Linguagem. V.3, n.1, p. 98-108, 2019. 